\title{
RESEARCH
}

Open Access

\section{miR-214-3p-Sufu-GLI1 is a novel regulatory axis controlling inflammatory smooth muscle cell differentiation from stem cells and neointimal hyperplasia}

Shiping He ${ }^{1,2+}$, Feng Yang ${ }^{1,3+}$, Mei Yang ${ }^{1,3}$, Weiwei An ${ }^{1}$, Eithne Margaret Maguire', Qishan Chen ${ }^{1,3}$, Rui Xiao ${ }^{1}$, Wei Wu', Li Zhang ${ }^{3,4^{*}}$, Wen Wang ${ }^{2^{*}}$ and Qingzhong Xiao ${ }^{1,5,6^{*}}$ (D)

\begin{abstract}
Background: Inflammatory smooth muscle cells (iSMCs) generated from adventitial stem/progenitor cells (AdSPCs) have been recognised as a new player in cardiovascular disease, and microRNA-214-3p (miR-214-3p) has been implicated in mature vascular SMC functions and neointimal hyperplasia. Here, we attempted to elucidate the functional involvements of miR-214-3p in iSMC differentiation from AdSPCs and unravel the therapeutic potential of miR-214-3p signalling in AdSPCs for injury-induced neointimal hyperplasia.

Methods: The role of miR-214-3p in iSMC differentiation from AdSPCs was evaluated by multiple biochemistry assays. The target of miR-214-3p was identified through binding site mutation and reporter activity analysis. A murine model of injury-induced arterial remodelling and stem cell transplantation was conducted to study the therapeutic potential of miR-214-3p. RT-qPCR analysis was performed to examine the gene expression in healthy and diseased human arteries.

Results: miR-214-3p prevented iSMC differentiation/generation from AdSPCs by restoring sonic hedgehog-gliomaassociated oncogene 1 (Shh-GLI1) signalling. Suppressor of fused (Sufu) was identified as a functional target of miR214-3p during iSMC generation from AdSPCs. Mechanistic studies revealed that miR-214-3p over-expression or Sufu inhibition can promote nuclear accumulation of GLI1 protein in AdSPCs, and the consensus sequence (GACCACCC A) for GLI1 binding within smooth muscle alpha-actin (SMaA) and serum response factor (SRF) gene promoters is required for their respective regulation by miR-214-3p and Sufu. Additionally, Sufu upregulates multiple

(Continued on next page)
\end{abstract}

\footnotetext{
*Correspondence: li.zhang.uk@gmail.com; wen.wang@qmul.ac.uk; q.xiao@qmul.ac.uk

+Shiping He and Feng Yang contributed equally to this work.

${ }^{3}$ Department of Cardiology, The First Affiliated Hospital, School of Medicine,

Zhejiang University, 79 Qingchun Road, Hangzhou 310003, Zhejiang, China ${ }^{2}$ Institute of Bioengineering, School of Engineering and Materials Science,

Queen Mary University of London, London EC1M 6BQ, UK

'Centre for Clinical Pharmacology, William Harvey Research Institute, Barts and The London School of Medicine and Dentistry, Queen Mary University of London, London EC1M 6BQ, UK

Full list of author information is available at the end of the article
}

(c) The Author(s). 2020 Open Access This article is licensed under a Creative Commons Attribution 4.0 International License, which permits use, sharing, adaptation, distribution and reproduction in any medium or format, as long as you give appropriate credit to the original author(s) and the source, provide a link to the Creative Commons licence, and indicate if changes were made. The images or other third party material in this article are included in the article's Creative Commons licence, unless indicated otherwise in a credit line to the material. If material is not included in the article's Creative Commons licence and your intended use is not permitted by statutory regulation or exceeds the permitted use, you will need to obtain permission directly from the copyright holder. To view a copy of this licence, visit http://creativecommons.org/licenses/by/4.0/ The Creative Commons Public Domain Dedication waiver (http://creativecommons.org/publicdomain/zero/1.0/) applies to the data made available in this article, unless otherwise stated in a credit line to the data. 
(Continued from previous page)

inflammatory gene expression (IFNY, IL-6, MCP-1 and S100A4) in iSMCs. In vivo, transfection of miR-214-3p into the injured vessels resulted in the decreased expression level of Sufu, reduced iSMC generation and inhibited neointimal hyperplasia. Importantly, perivascular transplantation of AdSPCs increased neointimal hyperplasia, whereas transplantation of AdSPCs over-expressing miR-214-3p prevented this. Finally, decreased expression of miR214-3p but increased expression of Sufu was observed in diseased human arteries.

Conclusions: We present a previously unexplored role for miR-214-3p in iSMC differentiation and neointima iSMC hyperplasia and provide new insights into the therapeutic effects of miR-214-3p in vascular disease.

Keywords: Adventitia stem/progenitor cells, Neointima formation, Inflammatory smooth muscle cell, Smooth muscle cell differentiation, MicroRNA-214, MicroRNAs, Suppressor of fused (Sufu)

\section{Introduction}

Smooth muscle cell (SMC) accumulation and phenotypic transition are critical steps for vascular remodelling in response to vascular injury. Although recent groundbreaking efforts, using SMC-restricted lineage-tracking techniques, have provided definitive evidence to support the conventional concept that medium SMCs are the main cellular origins of (neo)intimal SMCs upon injury [1-3], other studies also show that vascular stem/progenitor cells (SPCs), particularly SPCs located in the adventitial layer (namely AdSPCs), represent an additional source of the (neo)intimal SMCs in the atheroma $[4,5]$. There is compelling evidence to show that the blood vessel walls contain resident SPCs, such as smooth muscle progenitor cells that can migrate into the intima, where they differentiate into SMCs and contribute to atherosclerotic/neointima lesion formation and plaque stabilisation [6-12]. It is now widely acknowledged that inflammatory SMCs (iSMCs), co-expressing inflammatory cell markers and immature SMC markers and derived from bone marrow progenitor cells and/or vessel residential SPCs, are one of the major cellular sources of neointimal hyperplasia in severe vessel injury models [13-16]. Therefore, investigations into the mechanisms controlling iSMC differentiation from SPCs are essential for us to fully understand the pathogenesis of vascular diseases and remodelling and thus are of great clinical importance.

MicroRNAs (miRNAs) are endogenous, highly conserved single short strands of non-coding RNA. They have been reported as important regulators for stem cell differentiation, cardiovascular development and cardiac regeneration and are emerging as novel therapeutics as well as clinical biomarkers for cardiovascular diseases, including restenosis after vascular injury or stent implantation [17] and atherosclerosis. Although a handful miRNAs including miR-22 [18, 19], miR-34a [20, 21], miR-124 [22] and miR-143/145 cluster [23, 24] have recently been reported to play a role in modulating SMC differentiation from SPCs and controlling multiple processes of vascular diseases, further extensive investigations are warranted to fully elucidate the potential involvement of each miRNA in SMC differentiation and their significance in healthy and diseased arteries.

In particular, miR-214-3p has been reported to be highly expressed at early murine embryonic stages (E10.5 E12.5) in the heart [25], vasculature-rich adult organs and tissues $[25,26]$, differentiating SMCs [20], vascular endothelial cells and SMCs [26]. Functionally, miR-214-3p has been implicated in skeletal muscle differentiation [27-29], angiogenesis $[26,30]$, heart protection from ischemic injury [25], bone formation [31], arterial remodelling [32] and pathological perivascular fibrosis in hypertension [33]. The aforementioned studies describe a developmental and pathological role for miR-214-3p in the cardiovascular system, but as of yet, no report studying its regulatory role in the iSMC generation from AdSPCs within the context of injury-induced arterial remodelling has been carried out. Here, we report a novel role for miR-214-3p in governing iSMC generation from AdSPCs in the context of neointimal SMC hyperplasia.

\section{Materials and methods}

\section{Murine aortic AdSPC isolation, SMC or iSMC differentiation from AdSPCs}

The procedures for mouse aortic AdSPC isolation and culture are described in our previous study [6]. Undifferentiated AdSPCs (p3 p10) were cultured in SMC differentiation induction medium (DMEM supplemented with $5 \% \mathrm{FBS}$ and $5 \mathrm{ng} / \mathrm{ml} \mathrm{TGF} \beta 1$ ) in the absence (for SMC differentiation) or presence (for iSMC differentiation) of 50 $\mathrm{ng} / \mathrm{ml}$ TNF $\alpha$ for 2 to 6 days. The medium was refreshed every other day.

\section{Mouse femoral artery denudation injury and perivascular delivery of miR-214-3p agomiRs and neointima cell isolation}

The femoral artery denudation injury murine model has been widely used in preclinical studies to replicate the pathological processes of human percutaneous transluminal angioplasty $[34,35]$. Anesthetised C57BL/6 mice (8-week-old, male, 20 22 g, Charles River Laboratories) 
each underwent the wire-induced denudation injury surgical procedure as described previously [18, 21, 32]. For perivascular delivery of miR-214-3p, wire-injured femoral arteries were randomly assigned to a miR-214 or Cel-miR-67 agomiRs group for application with pluronic gel as described in our previous studies [18, 21, 32]. Briefly, after wire injury, $100 \mu \mathrm{l}$ of $30 \%$ pluronic gel containing chemically modified and cholesterol-conjugated $2.5 \mathrm{nmol}$ miR-214-3p or scrambled (Cel-miR-67) agomiRs was applied perivascularly to injured femoral arteries. The micrON ${ }^{\mathrm{Ts}}$ miRNA agomiRs were purchased from RiboBio (Guangzhou RiboBio Co., Ltd., China).

Procedures for cell isolation from the injured femoral arteries were similar to the protocols described in the previous studies [36-38]. Two weeks after injury and miRNA treatment, injured femoral arteries $(5 \sim 10 \mathrm{~mm})$ were dissected out for cell isolation using a similar protocol to AdSPC isolation as described previously [36-38]. The isolated single cells were re-suspended in SMC medium (DMEM with $10 \% \mathrm{FBS}$, and $1 \% \mathrm{P} / \mathrm{S}$ ) and transferred to six-well culture plate (for RNA isolation) or chamber slides (for immunostaining) pre-coated with $0.04 \%$ gelatin solution for up to 4 days prior to analysis.

\section{Mouse femoral artery denudation injury and perivascular transplantation of AdSPCs}

Eight-week-old male C57BL/6 mice (20 22 g) purchased from Charles River Laboratories were subjected to arterial injury and AdSPC transplantation. Briefly, arterial injury was induced by an endothelial denudation procedure as previously described [18, 21, 32]. Immediately after injury, $100 \mu \mathrm{l}$ Matrigel mixed with $20 \mu \mathrm{l}$ of cell culture medium (Vehicle control), or $1 \times 10^{6}$ AdSPCs transfected with control AgomiR (AdSPCs/Cel-miR-67) or miR-214-3p AgomiR (AdSPCs/miR-214), was randomly applied perivascularly to the injured femoral arteries. The injured arteries $(\sim 5.0$ $\mathrm{mm}$ ) were harvested at days 7 and 28 post-injury for gene expression, immunofluorescence staining and morphometric analysis.

Additional materials and methods used in this study are described in detail in the Online Supporting Information, including the protocols for AdSPC differentiation; morphometric analysis of arterial remodelling; lentiviral construction and infection; plasmid construction, transient transfection and luciferase assay; miRNA transfection; ELISA analysis of S100A4 and other cytokines; real-time quantitative PCR (RT-qPCR); immunoblotting; indirect immunofluorescent staining for cells; and chromatin immunoprecipitation (ChIP) assays.

\section{Statistical analysis}

Animals were randomly allocated to their experimental groups. Data collection and evaluation of all experiments were performed blinded to the group identity. The results are presented as mean \pm standard error of the mean (SEM). Statistical analysis was performed using GraphPad Prism (v8.3, GraphPad Software, USA). The Shapiro-Wilk normality test was used for checking the normality of the data. Two-tailed unpaired Student's $t$ test was used for comparisons between 2 groups, or one-way analysis of variance with a post hoc test of Tukey's analysis was applied when more than two groups were compared if the data displayed a normal distribution. Conversely, nonparametric Mann-Whitney $U$ test was used for comparing two groups, if the data did not display normal distribution or if the number of observations from each group was smaller than $5(n<5)$. Spearman's rank correlation analyses were conducted to characterise the relationships between the gene expression levels of miR-214-3p and Sufu in human arterial specimens. Alpha $=0.05$ was chosen as the significance level, and a value of $P<0.05$ was considered as statistically significant.

\section{Data availability}

Some data may not be made available because of privacy or ethical restrictions. All remaining data are contained within the article. Other detailed materials and methods were provided in the Online Supporting Information.

\section{Results}

A role for miR-214-3p in SMC differentiation from AdSPCs Isolated AdSPCs grew into colonies with a uniform morphology (Figure S1A) and were positive for the typical AdSPC markers Sox10, Sox17 and Nestin, but negative for other cell lineage markers (Figure S1B). Flow cytometry analysis showed that over $92 \%$ of these cells were double positive for Sox10 and Nestin (Figure S1C). RT-qPCR data showed that the respective expression levels of AdSPC marker and SMC genes were significantly decreased and increased in AdSPCs at a later stage (P12) (Figure S1D), suggesting that the AdSPCs can be maintained in vitro for a long period (up to 10 passages, P10) without apparent change of the gene expression. Therefore, AdSPCs between P3 and P10 were used in this study. As expected, AdSPCs were successfully induced to differentiate towards SMCs in response to TGF $\beta 1$ (Figure S2). To study the potential involvement of miRNAs in SMC differentiation from AdSPCs, we first detected if the expression levels of miR-22, miR34a and miR-214, the three top modulated miRNAs during SMC differentiation from embryonic stem cells [20], were altered in this process and found that miR-214-3p is the most upregulated miRNA among them in this SMC differentiation model (Figure S3A). miR-214-3p gain/loss-of-function experiments were conducted in AdSPCs to confirm a role for miR-214-3p in SMC differentiation from AdSPCs. As expected, miR-214-3p expression in AdSPCs was successfully upregulated and 
downregulated by miR-214-3p mimics and inhibitor, respectively (Figure S3B). Importantly, gene expression profiles showed that all four SMC genes examined here were significantly upregulated by miR-214-3p over-expression but downregulated by miR-214-3p inhibition (Figure S3C). These findings were confirmed at the protein level by Western blot assays (Figure S3D \& S3E), supporting a role for miR-214-3p in regulating SMC differentiation from AdSPCs.

\section{miR-214-3p inhibits TNFa-induced inflammatory SMC differentiation from AdSPCs}

Vascular SMCs can switch to a 'pro-inflammatory' phenotype, or inflammatory SMC (iSMC), in response to vascular injury, which promotes monocyte/macrophage recruitment into the vascular wall and triggers the pathological processes of atherosclerosis and arterial remodelling [39]. To mimic iSMC differentiation/generation from AdSPCs in vitro, differentiating AdSPCs were incubated with the pro-inflammatory cytokine, TNF $\alpha$. It is worth mentioning that TNF $\alpha$ alone failed to induce iSMC differentiation from AdSPCs in vitro; therefore, TNF $\alpha$ and TGF $\beta 1$ were used together to generate iSMCs in the following experiments. SMC differentiation was successfully induced in the presence of TGF $\beta 1$, as evidenced by the induction of two SMC-specific genes (SM $\alpha \mathrm{A}$ and SMmyh11), while no significant induction was observed with inflammatory genes (IFN $\gamma$, IL-6 and MCP-1/CCL2) and S100A4, a reported marker for the rhomboid SMC (RSMC) phenotype [40]. Interestingly, with the addition of TNF $\alpha$, the differentiating AdSPCs were primed to adopt an iSMC phenotype, whereby decreased expression levels of SMC genes and increased expression levels of the inflammatory genes and S100A4 were observed (Fig. 1a-c).

Multiple functional assays were conducted in mature SMCs with different phenotypes (serum-starved, 'synthetic' and 'contractile' SMCs) and iSMCs to further characterise the iSMC phenotype. Compared to 'synthetic' SMCs, iSMCs displayed a trend of increased SMC gene expression with a significant drop in the expression of extracellular matrix genes (Figure S4A). Among the cells, iSMCs expressed the highest level of inflammatory genes and produced the largest amount of inflammatory cytokines (Figure S4A \& S4B). Similarly, we observed the highest level of $\mathrm{NF \kappa B}$ activation in iSMCs (Figure S4C) compared to the other groups. Functionally, iSMCs grew and migrated faster than 'contractile' SMCs but slower than 'synthetic' SMCs (Figure S4D \& S4E). These data have collectively demonstrated that iSMCs display a distinct phenotype with moderate levels of matrix gene expression, cell proliferation and migration but a high level of inflammation, compared to either 'synthetic' or 'contractile' SMCs.

Importantly, we observed an increased expression level of miR-214-3p induced by TGF $\beta 1$ alone, and this was inhibited once TNF $\alpha$ was added into the differentiating AdSPCs (Fig. 1a), suggesting a role for miR-214-3p in these processes. Indeed, RT-qPCR data showed that while TNF $\alpha$ incubation significantly inhibited miR-214$3 p$ expression, transfection with miR-214-3p mimics significantly increased its expression (Fig. 1d). Crucially, we observed a similar trend with SMC gene expression to miR-214-3p expression, but an opposite trend for inflammatory genes and S100A4 (Fig. 1d-f), supporting a notion that miR-214-3p can rescue the iSMC phenotype induced by inflammation.

\section{Sonic hedgehog-glioma-associated oncogene 1 signal activation and modulation by miR-214-3p during iSMC differentiation}

Sonic hedgehog-glioma-associated oncogene 1 (Shh-GLI1) signalling has been extensively implicated in adventitial smooth muscle progenitor cell self-renewal and differentiation [41, 42] and blood vessel formation [43]. GLI1 reporter activity assays revealed that Shh-GLI1 signalling was significantly activated in TGF $\beta 1$-induced SMC differentiation, but its activity was almost completely abolished in iSMCs (Fig. 2a). Additionally, over-expression of miR-214$3 p$ in iSMCs could reverse GLI1 reporter activity (Fig. 2b), suggesting that miR-214-3p can modulate the Shh-GLI1 signalling pathway during iSMC differentiation from AdSPCs. This was further supported by gene expression profiles, in which our data showed that all three main components of the Shh-GLI1 signalling pathway (Shh, the transmembrane receptor [PTCH1] and the transcriptional effector [GLI1]), as well as its downstream target genes (Wnt1, Wnt4, Wnt9a and WISP1) were significantly activated by TGF $\beta 1$ treatment. These effects were blunted by the inclusion of TNF $\alpha$ into the differentiating AdSPCs (Fig. 2c). Moreover, the reverse phenomenon was observed once miR-214-3p mimics were introduced into iSMCs (Fig. 2d). Once activated by Shh binding to PTCHs, the smoothened receptor causes GLI1 relocalisation from the cytoplasm to the nucleus, where GLI1 regulates the gene expression through binding to the consensus GLI1-binding element (GACCACCCA) within its target gene promoters [44]. Western blot assay showed that nuclear, but not total, GLI1 protein levels were significantly modulated and regulated by miR-214-3p in iSMCs (Fig. 2e). This was further confirmed by immunofluorescence staining (Figure S5). Taken together, this data demonstrates that the Shh-GLI1 signalling pathway is closely modulated by miR-214-3p during iSMC differentiation/generation from AdSPCs.

\section{Identification of Sufu as the target gene of miR-214-3p during iSMC differentiation from AdSPCs}

Suppressor of fused (Sufu) negatively regulates hedgehog signalling through direct binding of GLI1 and by retaining GLI1 in the cytoplasm $[45,46]$. Interestingly, 




Fig. 1 miR-214-3p inhibits TNFa-induced inflammatory SMC differentiation from AdSPCs. a-c Passage 3-8 AdSPCs were cultured in SMC differentiation medium in the absence (vehicle (Veh)) or presence of $50 \mathrm{ng} / \mathrm{ml}$ TNFa for 4 days to allow for inflammatory SMC (iSMC) differentiation. Total RNA, protein and conditioned culture medium were harvested and subjected to RT-qPCR (a), Western blot (b) and ELISA analyses (c), respectively. $\mathbf{d}-\mathbf{f}$ miR-214-3p over-expression rescued mature/contractile SMC marker expressions and inhibited TNFa-induced inflammatory cytokine gene expression. AdSPCs were differentiated into iSMCs (DMEM containing $5 \mathrm{ng} / \mathrm{ml} \mathrm{TGF} \beta 1$ and $50 \mathrm{ng} / \mathrm{ml}$ TNFa) for 4 days, then transfected with miR-214-3p mimics (miR-214) or negative control (miR ctrl) and cultured for $48 \mathrm{~h}$ in the same culture medium. Total RNA, proteins and conditioned culture medium were harvested and subjected to RT-qPCR (d), Western blot (e) and ELISA (f) analysis, respectively. The data presented here are representative (top panels in $\mathbf{b}$ and $\mathbf{e}$ ) or mean \pm S.E.M. ( $\mathbf{a}, \mathbf{c}, \mathbf{d}, \mathbf{f}$ and bottom panels in $\mathbf{b}$ and $\mathbf{e})$ of five or six independent experiments ( $n=5$ or 6 ). ${ }^{*} P<0.05$ (vs vehicle/control); ${ }^{*} P<0.05$ (TGF $\beta 1 / T N F a$ vs TGF $\beta 1$ or TNFa/miR-214 vs TNFa/miR ctrl) (one-way ANOVA with a post hoc test of Tukey's analysis). miR-214 indicates miR-214-3p

we observed an opposite trend for Sufu (Fig. 3a, b) and miR-214-3p (Fig. 1a) expression during iSMC differentiation from AdSPCs, and that Sufu was negatively regulated by miR-214-3p (Fig. 3c-f) as demonstrated in miR-214-3p over-expression (Fig. 3c, d) and inhibition (Fig. 3e, f) experiments, respectively. Moreover, Sufu has been reported as a target of miR-214-3p in zebrafish [27], and both mouse and human Sufu 3'UTR harbour miR214-3p binding sites, indicating that Sufu is the mRNA target of miR-214-3p during iSMC differentiation from AdSPCs. This was supported by luciferase data with Sufu
3'UTR luciferase reporter, in which we found that the reporter activity was dramatically supressed by miR-214-3p over-expression, and the conserved miR-214-3p binding site within Sufu 3'UTR is required for Sufu gene suppression by miR-214-3p since the inhibitory effect of miR-214$3 p$ over-expression on Sufu 3'UTR reporter activity was almost completely abolished once the binding site was mutated (Fig. 3g). Taken together, this data clearly demonstrates that Sufu is a true mRNA target of miR-214$3 p$ in the context of iSMC differentiation/generation from AdSPCs. 







Fig. 2 Sonic hedgehog-glioma-associated oncogene 1 (Shh-GLI1) signal activation and modulation by miR-214-3p during iSMC differentiation. a, b Luciferase activity assays to examine Shh-GLI signalling activity. AdSPCS were transfected with GLI reporter constructs and subjected to various treatments indicated in respective figures. Two days later, total cell lysates were harvested and subjected to luciferase activity assays. c, $\mathbf{d}$ RT-qPCR detection of Shh-GLI target gene expression. e miR-214-3p promotes GLI1 nuclear translocation. AdSPCs were subjected to similar treatments described in Fig. 1 d-f. Total cell lysate and nuclear proteins were extracted and subjected to Western blot analysis. The data presented here are representative (left panel in e) or mean \pm S.E.M. (a-d and right panel in e) of five independent experiments $(n=5)$. ${ }^{*} P<0.05$ (vs vehicle/control); ${ }^{*} P<0.05$ (TGF $\beta 1 / T N F a$ vs TGF $\beta 1$ or TNFa/miR-214 vs TNFa/miR ctrl) (one-way ANOVA with a post hoc test of Tukey's analysis). miR-214 indicates miR-214-3p

\section{Sufu mediates SMC gene expression by modulating GLI1} nuclear translocation

Compared to the respective control cells, Sufu knockdown significantly upregulated SMC gene expression at both the mRNA (Fig. 4a) and protein (Fig. 4b) levels, while the opposite effect was observed when overexpressing Sufu in the differentiating AdSPCs (Figure S6A), suggesting that Sufu functions as a negative regulator of SMC marker gene expression. This was further confirmed by SMC gene promoter activity assays (Fig. 4c and S6B), indicating that Sufu regulates SMC gene expression at a transcriptional level. RT-qPCR data showed no significant difference for GLI1 mRNA expression levels between control and Sufu knockdown AdSPCs (Figure S6C), while data from both Western blot (Fig. 4d, e) and immunofluorescence staining (Figure S6D) assays revealed that Sufu inhibition in the differentiating AdSPCs results in nuclear accumulation of the GLI1 protein. Interestingly, two GLI1 binding sites were identified within the SM $\alpha \mathrm{A}$ gene promoter, and we found that both GLI1 binding sites were important for Sufu-mediated SM $\alpha$ A gene suppression during iSMC differentiation from AdSPCs (Fig. 4f). Finally, chromatin immunoprecipitation (ChIP) assay data revealed that GLI1 binds directly to regions spanning around GLI1-binding element of SM $\alpha \mathrm{A}$ gene promoters, and this binding was dramatically enhanced by Sufu 



Fig. 3 Identification of Sufu as the target gene of miR-214-3p during TNFa-induced iSMC differentiation from AdSPCS. a, b Sufu is closely modulated during iSMC differentiation from AdSPCs. c, d miR-214-3p over-expression in iSMCs inhibits Sufu gene expression. e, $\mathbf{f}$ Upregulation of Sufu by miR214-3p inhibition. AdSPCs were differentiated into iSMCs for 4 days, then transfected with miR-214-3p inhibitor or negative control (miR ctrl) and cultured for $48 \mathrm{~h}$ in the same culture medium. Total RNAs and proteins were harvested and subjected to RT-qPCR (e) and Western blot (f) analysis, respectively. $\mathbf{g}$ The binding site is required for miR-214-3p-mediated Sufu gene repression. The potential wild-type binding site (WT) for miR-214-3p within Sufu gene $3^{\prime} U T R$ and its mutant (BS ${ }^{\text {mut }}$ ) are depicted in this illustration (left). miR-214-3p mimics or negative control (miR ctrl) was cotransfected into iSMCs with wild-type Sufu 3'UTR reporter (WT) or miR-214-3p binding site mutants [miR-214BS ${ }^{\text {mut]}}$, respectively. Luciferase activity assay was measured at $48 \mathrm{~h}$ post-transfection. The data presented here are representative (left panels in $\mathbf{b}$, $\mathbf{d}$ and $\mathbf{f}$ ) or mean \pm S.E.M. of five (a, c, e and right panels in $\mathbf{b}, \mathbf{d}$ and $\mathbf{f}, n=5$ ) or eight $(\mathbf{g}, n=8)$ independent experiments. ${ }^{*} P<0.05$ (vs vehicle/miR ctrl); ${ }^{*} P<0.05$ (TGF $\beta 1 /$ TNFa vs TGF $\beta 1$ or TNFa/ miR-214 vs TNFa/miR ctrl). (One-way ANOVA with a post hoc test of Tukey's analysis for $\mathbf{a}-\mathbf{d}$; unpaired $t$ test for $\mathbf{e}-\mathbf{g}$ ). miR-214 indicates miR-214-3p

inhibition (Fig. 4g). Altogether, the above data suggests that Sufu represses SMC gene expression by modulating the Shh-GLI1 signalling pathway.

\section{Sufu controls SMC gene expression by regulating the transcription factor, SRF}

Luciferase activity assays showed that Sufu knockdown in the differentiating AdSPCs significantly activates SMC gene promoter activities (Figure S7A \& S7B) and that SRF binding element (CArG) mutation in SMC gene promoter reporters could almost abrogate their transcriptional activity in response to Sufu inhibition (Figure S7A \& S7B), inferring an important role for SRF in Sufu-mediated SMC gene regulation. We found that Sufu over-expression inhibited SRF gene expression (Figure S7C), while Sufu knockdown promoted its expression (Figure S7D). A 




Fig. 4 Sufu mediates SMC gene expression by modulating GLI1 nuclear translocation. $\mathbf{a}$, b Sufu knockdown upregulated SMC gene expression. AdSPCs were infected with non-target (sh-NT) or Sufu (sh-Sufu) shRNA lentivirus, followed by iSMC differentiation. Total RNAs and proteins were harvested and subjected to RT-PCR (a) and Western blot (b) analyses, respectively. c SMC gene promoter activity was upregulated by Sufu inhibition. AdSPCs infected with sh-NT or sh-Sufu lentivirus were transfected with SMC gene promoters (pGL3-SMaA or SM22a). Two days later, total cell lysates were harvested and subjected to luciferase activity assays. d, e Sufu knockdown increases GLI1 nuclear translocation. AdSPCS were subjected to similar treatments described in $\mathbf{a}$ and $\mathbf{b}$. Total cell lysate and nuclear proteins were extracted and subjected to Western blot analysis. $\mathbf{f}$ Two GLI1 binding sites within the SMaA gene promoter region are required for SMaA gene upregulation by Sufu knockdown in AdSPCs. The potential wild-type binding site (WT) of GLI1 within the SMaA gene promoter region and its mutants (GLI1 ${ }^{\text {mut }}$ ) is depicted in this illustration (top). AdSPCs infected with sh-NT or sh-Sufu lentivirus were transfected with wild-type and mutated SMaA gene promoter reporters as indicated. Luciferase activity assay was measured at $48 \mathrm{~h}$ post-transfection. $\mathbf{g}$ Sufu inhibition increases GLI1 enrichment within the SMaA gene promoter. ChIP assays were performed using antibodies against GLI1 or normal IgG. PCR amplifications of the adjacent regions were included as an additional control for specific promoter DNA enrichment. The data presented here are representative (left panel in $\mathbf{b}$, and $\mathbf{d}$ ) or mean \pm S.E.M. (a, $\mathbf{c}, \mathbf{e}-\mathbf{g}$ and right panel in b) of five independent experiments $(n=5) .{ }^{*} P<0.05,{ }^{* *} P<0.01$ (vs sh-NT, unpaired $t$ test)

similar effect was observed in luciferase activity assays with an SRF gene promoter construct (Figure S7E). Importantly, luciferase activity assays, using the SRF gene promoter construct containing the mutated GLI1 binding site, revealed a critical role for the GLI1-binding site within the SRF gene promoter in SRF gene suppression by Sufu (Figure S7F). Moreover, ChIP assays showed a significant enrichment of GLI1 within the SRF gene promoter in AdSPCs with Sufu knockdown (Figure S7G). Taken together, the above findings demonstrate that Sufu regulates SMC gene expression during iSMC differentiation from AdSPCs by modulating the binding of GLI1 to SRF gene promoter and controlling SRF transcriptional activity.

\section{A regulatory role for the Sufu-GLI1 signal axis in inflammatory gene expression during iSMC differentiation from AdSPCs}

The Sufu-GLI1 signal axis has been reported to play a critical role in the intestinal inflammatory response, and 
decreased GLI1 activity predisposes to a heightened myeloid response to inflammatory stimuli in inflammatory bowel diseases [47]. We wondered if this axis also played a role in inflammatory gene expression and iSMC differentiation from AdSPCs. RT-qPCR data showed that Sufu inhibition (increased GLI1 activity and nuclear accumulation as shown in Fig. 4d, e) significantly inhibited the expression levels of all three inflammatory genes and S100A4 (Fig. 5a), while Sufu over-expression had the opposite impact (Fig. 5b). A similar effect was confirmed at the protein level in ELISA assays (Fig. 5c, d), as well as at the transcriptional level, as shown by luciferase activity assays with IL- 6 and MCP-1/ CCL2 gene promoter reporters (pmIL-6 FL and pMCP-Luc) (Fig. 5e, f). Collectively, this data demonstrates that Sufu serves as a positive regulator in inflammatory gene regulation by negatively regulating GLI1 activity during iSMC differentiation from AdSPCs.
miR-214-3p over-expression in injured arteries decreases iSMC formation

Similar to our previous studies [18, 21, 32], a neointimal layer was observed in the injured arteries treated with Cel-miR-67 agomiRs, while locally enforced expression of miR-214-3p resulted in a smaller neointimal layer (Figure S8A). As expected, cells isolated by enzymatic digestion from the normal medial layer (SMCs/Sham) consistently exhibited a spindle-shaped phenotype with the classic 'hill-and-valley' growth pattern at confluence, while cells isolated from the media/neointima layer of the injured arteries displayed a phenotype resembling RSMCs, as previously reported [48]. Interestingly, miR214-3p over-expression in the injured arteries reverted the injury-induced R-SMC phenotype to a classic one (Figure S8B). Data from immunofluorescence staining revealed that cells with R-SMC phenotype were positive


Fig. 5 Sufu positively regulates TNFa-induced inflammatory gene expression in AdSPC-derived iSMCs. a-d Inflammatory gene expression in iSMCS was positively modulated by Sufu. AdSPCs were infected with non-target (sh-NT) or Sufu (sh-Sufu) shRNA lentivirus (a, c), or control ( $p C D H)$ or Sufu over-expressing (pCDH-Sufu) vector (b, d), followed by iSMC differentiation for 4 days. Total RNAs and conditioned culture medium were harvested and subjected to RT-PCR $(\mathbf{a}, \mathbf{b})$ and ELISA (c, d) analyses, respectively. e, $\mathbf{f}$ Luciferase activity assays. AdSPCs infected with sh-NT or sh-Sufu (e), or pCDH or pCDH-Sufu (f) were transfected with IL-6 (pmlL-6 FL) or MCP-1/CCL2 (pMCP-Luc) gene promoter reporters as indicated in the figures, followed by iSMC differentiation. Two days later, total cell lysates were harvested and subjected to luciferase activity assays. The data presented here are mean \pm S.E.M. of five ( $n=5$ in $\mathbf{a}, \mathbf{b}$, e and $\mathbf{f}$ ) or six ( $n=6$ in $\mathbf{c}$ and $\mathbf{d}$ ) independent experiments. ${ }^{*} P<0.05$ (vs sh-NT or $p C D H$, unpaired $t$ test) 
for SM $\alpha \mathrm{A}$ and IL-6, and miR-214-3p over-expression significantly reduced iSMC formation (Figure S8C \& S8D). Compared with SMCs, expression levels of miR214-3p and SMC contractile genes (SM $\alpha \mathrm{A}$ and SMmyh11) were significantly decreased, while that of Sufu (miR-214-3p target gene), IL-6 and S100A4 (iSMC markers) were dramatically increased in the neointimal cells treated with control Cel-miR-67 agomiRs (Figure S8E). Importantly, perivascular transfection with miR-214-3p agomiR resulted in an increased level of miR-214-3p in the neointimal cells, which consequently reversed the above-described gene expression profiles (Figure S8E). Altogether, the above data demonstrate that miR-214-3p inhibits iSMC formation within the injured arterial walls.

\section{Transplantation of AdSPCs increases adverse arterial remodelling in response to injury, while miR-214-3p over- expression in AdSPCs reverses this effect}

Triple immunofluorescence staining of the injured segments of the femoral arteries transplanted with GFPlabelled AdSPCs with antibodies against GFP, SM $\alpha$ A and S100A4 showed that the transplanted AdSPCs could differentiate into iSMCs (cells are positive for GFP, $\mathrm{SM} \alpha \mathrm{A}$ and S100A4) within the injured arterial walls (Figure S9). To further explore the functional implication of miR-214-3p in controlling iSMC generation from AdSPCs in the context of angioplasty-induced vascular remodelling, 8-week-old male mice were subjected to arterial injury and AdSPC transplantation as indicated in the figures. As previously reported [34, 35], the neointimal lesion was almost undetectable at 1 week following injury; therefore, aortic tissues at 1 week post-injury were harvested and subjected to gene expression analysis. AdSPC transplantation resulted in a trend of decreased miR-214-3p and SM $\alpha \mathrm{A}$ expression and significantly increased Sufu, S100A4 and inflammatory gene expression (Fig. 6a). Thus, further supporting previous observations that transplanted AdSPCs can acquire an iSMC phenotype during injury-induced arterial remodelling. Importantly, local transplantation of miR-214-3p over-expressing AdSPCs dramatically increased vascular miR-214-3p and SM $\alpha \mathrm{A}$ levels but significantly decreased expression of other genes (Fig. 6a). Consequently, after 28 days, neointimal formation was induced by wire injury of the femoral artery in the mice treated with vehicle control. This was further increased by AdSPC transplantation; however, such advanced arterial remodelling response was prevented in mice transplanted with miR-214-3p over-expressing AdSPCs (Fig. 6b, c). Taken together, our data confirmed a preventive effect of miR-214-3p on neointimal SMC hyperplasia, likely through its inhibitory role in
iSMC differentiation/generation from AdSPCs in response to vascular injury.

\section{Expression profiles of miR-214-3p and Sufu in the healthy} and diseased human vessels

To further validate and translate our findings into a clinical setting, the gene expression levels of miR-214-3p and Sufu and their possible relationship were examined in healthy and diseased femoral arterial (FA) specimens collected in our previous study [18]. RT-qPCR data showed decreased expression levels for the miR-214-3p gene, with an increased gene expression levels for Sufu in diseased femoral arteries, compared with healthy arteries (Fig. 7a). Importantly, we observed a significant inverse relationship between miR-214-3p and Sufu in both healthy and diseased femoral arterial specimens (Fig. 7b). Thus, the above human data supports the functional implication of miR-214-3p and its target gene Sufu in human angiographic restenosis.

\section{Discussion}

The potential contributions of residential AdSPCderived iSMCs to neointimal SMC hyperplasia and the underlying molecular mechanisms of iSMC differentiation/generation from the AdSPCs have yet to be fully recognised and elucidated and require further investigation. In the current study, we attempted to address this unexplored avenue by uncovering a novel role for miR214-3p in modulating SMC differentiation and iSMC generation from AdSPCs in vitro and in vivo (Fig. 7c). Importantly, our data showed that miR-214-3p is highly upregulated during SMC differentiation from AdSPCs induced by TGF $\beta 1$ and provided clear evidence to suggest an important role for miR-214-3p in this process. Moreover, the addition of TNF $\alpha$ into the differentiating SMCs could prime them into an iSMC phenotype, a process which miR-214-3p over-expression could reverse. We have also demonstrated for the first time that the miR214-3p-Sufu-GLI1 axis is one of the key signalling pathways responsible for iSMC differentiation/generation from AdSPCs. Mechanistically, we have confirmed that Sufu is an authentic downstream target of miR-214-3p during iSMC differentiation from AdSPCs and have identified Sufu as a novel transcriptional repressor of SMC contractile genes and an important transcriptional activator of inflammatory genes. Our ex vivo and in vivo data have shown for the first time that AdSPCs can be induced to differentiate into iSMCs within injured arteries and that transplanted AdSPCs over-expressing miR-214-3p onto injured arteries can reverse the process of iSMC differentiation from AdSPCs and prevent post-angioplasty restenosis. Importantly, our human data also support a potential role for miR-214-3p and Sufu in human atherosclerosis. 






AdSPCs/Cel-miR-67
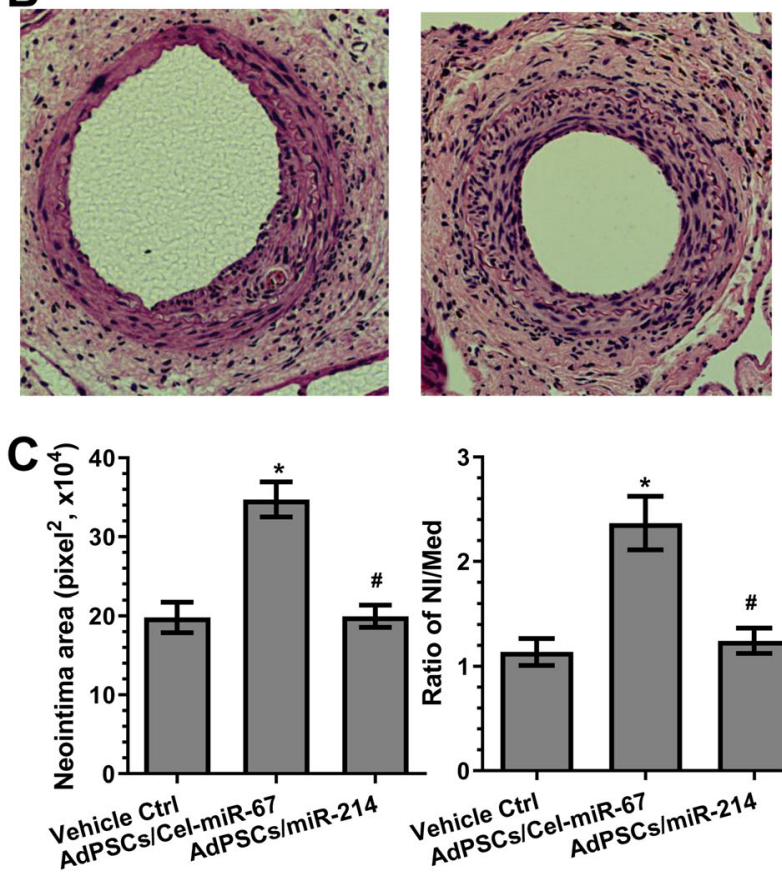



AdSPCs/miR-214


Fig. 6 Transplantation of AdSPCs increases adversely arterial remodelling in response to injury, while miR-214-3p over-expression in AdSPCs reverses such processes. Eight-week-old male mice were randomly subjected to arterial injury and AdSPC transplantation. After injury, $100 \mu$ l of Geltrex contained culture medium (vehicle ctrl) or $1 \times 10^{6}$ AdSPCs transfected with control AgomiR (AdSPCs/Cel-miR-67) or miR-214-3p AgomiR (AdSPCs/miR-214) was immediately applied and packed around the injured vessel. One (a) or 4 (b, c) weeks later, injured segments of the femoral arteries were harvested and subjected to the following studies as indicated. a RT-qPCR detection of gene expressions in the injured arteries. The data presented in a are mean \pm S.E.M. of five independent experiments (femoral arteries from 3 5 mice were pooled for each experiment, $n=5$ experiments). b, c Morphometric analysis of the wire injury-induced neointima formation. Paraffin sections from the indicated groups ( $n=10$ mice for each group) were prepared and subjected to H\&E staining analyses. Representative images (b) and morphological characteristics including the neointimal area, neointimal/media (N/M) ratio and media area (c) were presented here. ${ }^{*} P<0.05$ (vs vehicle Ctrl). ${ }^{\#} P<0.05$ (AdSPCs/miR-214 vs AdSPCs/Cel-miR-67) (one-way ANOVA with a post hoc test of Tukey's analysis)

miR-214-3p belongs to the miR-199a-214 cluster, which is encoded by DNM3os that is transcribed from the opposite strand of the DNM3 gene [49]. Differing roles for miR-214-3p in cardiac cell functions and associated diseases have been well-documented in the literature. Reasons for the reported discrepancies are likely due to the fact that different cell systems and animal models were used among these studies, suggesting that miR-214-3p plays a divergent role in various diseases and the functional implication of miR-214-3p is cell context-dependent. A functional role for miR-214-3p in mature vascular SMCs and injury-induced arterial remodelling has been reported in our previous study. In that study, we reported that miR-214-3p controls both vascular SMC proliferation and migration, and miR-214-3p over-expression in the injured arteries reduces neointimal SMC hyperplasia by modulating vascular SMC proliferation [32]. In this study, we provide new perspectives on the role of miR-214-3p in iSMC generation from AdSPCs in the context of injury-induced arterial remodelling. Firstly, we explore the novel concept of AdSPCs as an additional cellular source for neointimal SMCs, while previously, we kept within the traditional confines of mature vascular SMC phenotypic modulation as the cause of neointimal SMC 



C



Fig. 7 (See legend on next page.) 




hyperplasia. Secondly, we have confirmed an additional function for miR-214-3p, namely that even in the presence of strong inflammatory stimuli, miR-214-3p can reverse the inflammatory phenotype of AdSPC-derived iSMCs into a contractile phenotype in vitro and in vivo. Thirdly, a novel underlying mechanism for iSMC differentiation/generation from AdSPCs has been documented in this study. Specifically, we demonstrate that Sufu is the true target gene of miR-214-3p in the context of iSMCs and injury-induced arterial remodelling. Sufu exerts its functions by allowing GLI1, the nuclear transcriptional effector of Shh signal pathway, to translocate into the nucleus to regulate relevant target gene expression. Finally, we are also able to translate our findings from mice into men by documenting the gene expression profiles of miR-214-3p and Sufu, as well as their relationships in both healthy and diseased human arteries. Therefore, findings from this study and previous ones support an important role of miR-214-3p in iSMC differentiation/generation from AdSPCs, vascular SMC biology and arterial remodelling induced by injury.

One of the new aspects of this study is the establishment of a reliable cellular model to study iSMC differentiation/ generation from AdSPCs. Apart from the classical 'contractile' to 'synthetic' phenotypic modulation model, extensive evidence also suggests that vascular SMCs can be primed to another distinct phenotype, namely the 'pro-inflammatory' phenotype or iSMCs, in response to vascular injury or inflammatory stimuli. These iSMCs contribute to vascular disease progression and are a pervasive feature of atherosclerotic lesion formation [39] and arterial remodelling [50]. However, the majority of previous studies used mature vascular SMCs as a cellular model to study iSMCs and relevant signal pathways [51-53]. Although the existence and functional importance of stem/progenitor cell-derived SMCs in vascular diseases has been increasingly recognised by vascular biology researchers, there is a lack of cellular models with which to study AdSPC-derived iSMCs and the molecular mechanisms involved. In this study, we tested the hypothesis that exposure of the differentiating AdSPCs/SMCs with inflammatory stimuli could induce an iSMC phenotype from AdSPCs. Indeed, we found that inclusion of TNF $\alpha$ into the SMC differentiation medium could prime AdSPC-derived SMCs to an iSMC phenotype (Fig. 1 and S4), which is characterised by the decreased expression levels of SMC contractile genes and increased expression levels of inflammatory genes. As expected, compared to mature SMCs with different phenotypes, iSMCs produce and secrete the highest amount of inflammatory cytokines, IFN $\gamma$, IL-6 and MCP-1/CCL2. Interestingly, AdSPCderived iSMCs also express high levels of S100A4, the reported marker for R-SMCs [40]. Although our iSMCs morphologically resemble R-SMCs [48], it would be difficult to claim that iSMCs are the same as or similar to RSMCs, or equally represent a separate SMC phenotype, without a side-by-side comparison in terms of their functionalities, pathological contributions to vascular diseases and global gene/protein expression profiles.

Another new finding from this study is the identification of Sufu as a functional target gene of miR-214-3p in the context of iSMC differentiation from AdSPCs. Although multiple miR-214-3p target genes have been reported in various cellular contexts and diseases (e.g., NCKAP1 [32], N-RAS [28], ITCH [54], Quaking [26] and Ncx1), none of them seems to play a role in iSMC differentiation from AdSPCs. Instead, through our combined efforts, we have demonstrated that Sufu is a novel target gene of miR-214-3p in iSMCs. The Shh-GLI1 pathway has been reported as a key fate-determining factor for residential vascular stem cells [55]. Several components of the Shh-GLI1 signal pathway (e.g., Shh, patched-1, patched-2 and GLI1) have been used to mark the resident vascular SPCs $[42,56]$. Importantly, Sufu is a well-known negative regulator of hedgehog signalling. It serves as a docking protein to retain the nuclear effector protein of Shh signalling, GLI1, in the cytoplasm, preventing it from being shuttled into the nuclei to trigger the transcriptional programme $[45,46]$, pointing to a possible signalling pathway for Sufu in vascular stem/ progenitor cell development and differentiation. As it stands, this has yet to be reported in the current literature, and the mechanism through which Sufu (or ShhGLI1 signal axis) is modulated in the context of SMC differentiation from AdSPCs remains elusive. In this 
study, we provide first-hand evidence to support that the Shh-GLI1 signal axis is activated during iSMC differentiation from AdSPCs, Sufu is negatively regulated by miR214-3p and that the Shh-GLI1 signal axis is closely modulated by miR-214-3p/Sufu in iSMCs. NCKAP1 has previously been identified as a target gene of miR-214-3p in mature vascular SMCs [32]; however, we found no evidence to support the NCKAP1 as the functional target gene during iSMC differentiation from AdSPCs. These findings further support our understanding that any given miRNA can play divergent roles in response to different microenvironmental clues by regulating specific gene expression and that the way in which miRNAs regulate their target genes is dependent on the cellular context.

One of the novel mechanistic findings reported here is that Sufu could serve as a negative or positive regulator of SMC and inflammatory gene expression, respectively. We have demonstrated that Sufu is a new mediator to govern iSMC differentiation by regulating SMC-specific gene (SM $\alpha \mathrm{A}$ and SM-myh11), SMC transcriptional factor SRF and inflammatory genes (IFNy, IL-6 and MCP-1/CCL2) through a transcriptional mechanism. Our data shows that Sufu exerts transcriptional regulation through modulation of GLI1 nuclear translocation. Data generated from luciferase activity (Figs. 4c, f; 5e, f; and S6B, S7) and CHIP assays (Fig. 4g and S7G) provide multiple lines of evidence to support this mechanism. Specifically, our data shows that (1) Sufu negatively regulates SMC gene promoter activity (pGL3-SM $\alpha$ A, pGL3SM22 $\alpha$ and pGL3-SRF), (2) GLI1-binding sites within SM $\alpha \mathrm{A}$ and SRF gene promoters are required for these gene transduction regulated by Sufu, (3) GLI1 nuclear accumulation and its binding to the promoter DNA of SMC-specific genes (SM $\alpha \mathrm{A}$ and SRF) can be modulated by Sufu, and (4) the promoter activity of inflammatory genes (IL-6 and MCP-1/CCL2) is positively regulated by Sufu in iSMCs. The above-mentioned evidence clearly supports the claim that Sufu/GLI1 may function as a transcriptional activator or repressor for distinct sets of genes in response to the micro-environmental clues. Similarly, we have also noticed that S100A4 gene expression is closely modulated by the miR-214-3p/Sufu axis during iSMC differentiation from AdSPCs. Therefore, it would be very interesting to investigate whether Sufu regulates S100A4 gene expression through a similar mechanism.

\section{Conclusions}

In the current study, we have successfully uncovered the functional involvements of miR-214-3p in iSMC differentiation/generation from residential AdSPCs in the context of vascular remodelling after injury (Fig. 7c). Moreover, the newly identified target gene Sufu is at least partially responsible for miR-214-3p-mediated
iSMC differentiation/generation from AdSPCs. Therefore, the findings presented in this study suggest that modulating miR-214-3p-Sufu-GLI1 axis could be a potential therapeutic tool for vascular diseases such as atherosclerosis and post-angioplasty restenosis.

\section{Supplementary Information}

Supplementary information accompanies this paper at https://doi.org/10. 1186/s13287-020-01989-W.

\section{Additional file 1: Table S1 and Supporting Methods.}

Additional file 2: Figure S1. Characterization of adventitia stem/ progenitor cells (AdSPCs). (A) Phase-contrast image showing the primary culture of AdSPCS (P0). (B)AdSPCs at passage 3 8 were subjected to immunofluorescence staining with antibodies against AdSPC and other cell lineage markers, namely Sox10/FSP1 (fibroblast marker), Sox17/CD31 (endothelial cell marker), and Nestin/SM-NHC (SMC marker), respectively. (C) Flow cytometry analysis of AdSPC markers (Sox10 and Nestin) expression in AdSPCs at passage 3. (D) Gene expression profiles in AdSPCs at the indicated passage number $(P)$. The data presented here are representative $(A-C)$ or mean \pm S.E.M. (D) of five independent experiments. ${ }^{*} P<0.05$ (versus P3, one-way ANOVA with a post hoc test of Tukey's analysis).

Additional file 3: Figure S2. SMC differentiation from AdSPCs. Passage 3-8 AdSPCs were cultured in SMC differentiation medium (DMEM supplemented with $5 \%$ FBS and $5 \mathrm{ng} / \mathrm{ml}$ TGF $\beta 1$ ) for the indicated time to allow for SMC differentiation. Total RNAs and proteins from undifferentiated AdSPCs (Od) or differentiating AdSPCs at day 2, 4,6 and 8 were harvested and subjected to RT-qPCR (A) and Western blot (B) analyses, respectively. (C) Mature SMC marker expression in AdSPC-derived SMCs. Day 8 differentiated SMCs were stained with antibodies against SMaA and SM-MHC. The data presented here are representative images (left panel in $B$, and C) or mean \pm S.E.M. (A, and right panel in B) of five independent experiments. ${ }^{*} P<0.05$ (versus $0 d$, one-way ANOVA with a post hoc test of Tukey's analysis)

Additional file 4: Figure S3. miR-214 promotes SMC differentiation from AdSPCs. (A) Increased expression of miR-214 in AdSPCs in response to TGF $\beta 1$. (B-E) miR-214 modulates SMC marker expressions. Day 2 differentiating AdSPCs were transfected with miR-214 mimics, inhibitor or respective negative control (miR ctrl), and cultured for 2 3 days, followed by RT-qPCR (B \& C) and western blot ( $D \& E$ ) analyses, respectively. The data presented here are representative (up panels in $D \& E$ ) or mean \pm S.E.M. (A-C, and bottom panels in D \& E) of five independent experiments. ${ }^{*} P<0.05$. One-way ANOVA with a post hoc test of Tukey's analysis for $A$ \& C, unpaired t-test for B. miR-214 indicates miR-214-3p.

Additional file 5: Figure S4. Characterisation of iSMC phenotype. Mature SMCs were subjected to serum starvation for 48 hours, followed by the indicated treatments for additional 24 hours. Total RNAs and conditioned culture medium harvested from SMCs treated with vehicle (serum-starved SMCs, ssSMCs), 5ng/ml TGF 31 ('contractile' SMCs, conSMCs), $10 \mathrm{ng} / \mathrm{ml}$ PDGF-BB ('synthetic' SMCs, synSMCs), and iSMCs differentiated from AdSPCs (iSMCs) were subjected to RT-qPCR (A) and ELISA analyses (B), respectively. (C) Luciferase activity assays detected NFKB activation in cells with the indicated treatments. (D) BrdU incorporation assays to detect cell proliferation. (E) Trans-well migration assays detected cell migration under 30ng/ml PDGF-BB stimulation. The data presented here are representative images (left panels in E) or mean \pm S.E.M. (A-D, right panel in E) of five independent experiments $(n=5)$. ${ }^{*} \mathrm{P}<$ 0.05 (versus ssSMCs), ${ }^{*}<0.05$ (versus synSMCs) (one-way ANOVA with a post hoc test of Tukey's analysis).

Additional file 6: Figure S5. GLI1 cellular location was modulated by miR-214-3p. AdSPCs were differentiated into iSMCs (DMEM containing $5 \mathrm{ng} / \mathrm{ml} \mathrm{TGF \beta 1}$ and 50ng/ml TNFa) for 4 days, then transfected with miR214-3p mimics (miR-214) or negative control (miR ctrl), and cultured for 48 hours in the same culture medium. Cells were fixed and subjected to immunofluorescence staining (A). Fifty cells were randomly selected for quantification by Image J free software (Version 1.47, RRID:SCR_003070) 
from each treatment. Mean fluorescence intensity (MFI) of nuclear (B) and cytoplasmic (C) GLI1 (green), as well as DAPI (blue) from the same cells were quantified, and the ratio of MFI of GLI1 over DAPI were calculated accordingly. Veh indicates vehicle control for TNFa. The data presented here are representative (A) or mean \pm S.E.M. (B \& C) of fifty cells $(n=50)$. ${ }^{*} \mathrm{P}<0.05$ (vs veh/miR ctrl); ${ }^{\#} \mathrm{P}<0.05$ (TNFa/miR-214 vs TNFa/miR ctrl) (oneway ANOVA with a post hoc test of Tukey's analysis). miR-214 indicates miR-214-3p.

Additional file 7: Figure S6. Sufu controls SMC gene expression and GLI1 cellular location. (A) SMC gene expression is negatively regulated by Sufu. AdSPCs (p3 p8) were infected with control ( $p C D H)$ or Sufu overexpression ( $\mathrm{pCDH}$-Sufu) lentivirus and cultured in iSMC differentiation induction medium for 2 3 days. The expression levels of a panel of SMC specific genes was examined by RT-qPCR analysis. (B) Sufu overexpression inhibited SMC gene promoter activity. AdSPCs infected with pCDH or pCDH-Sufu were transfected with SMC gene promoter reporters (pGL3-SMaA or pGL3-SM22a) as indicated. Luciferase activity assays were conducted at 48 hours post-transfection. (C) GLI1 gene expression was not affected by Sufu over-expression. (D) Sufu knockdown promotes GLI1 protein accumulation in nuclei. AdSPCs were infected with non-target (sh-NT) or Sufu (sh-Sufu) shRNA lentivirus, followed by iSMC differentiation. Cells were fixed and subjected to immunofluorescence staining with GLI1 antibody. Data presented here are representative images (D) or Mean \pm S.E.M of five or six independent experiments ( $n=5$ or 6 , unpaired ttest)

Additional file 8: Figure S7. Sufu controls SMC gene expression through regulating SRF. (A-B) Serum response factor (SRF) binding sites within SMC gene promoters are required for Sufu-mediated SMC gene repression. AdSPCs infected with non-target (sh-NT) or Sufu (sh-Sufu) shRNA lentivirus were transfected with wild type (WT) SMC gene promoter reporters ( $\mathrm{pGL} 3-\mathrm{SMaA}$ or $\mathrm{pGL3}-\mathrm{SM} 22 \mathrm{a}$ ), or SRF binding site mutants [SRF ${ }^{\text {mut }}$, respectively. Luciferase activity assay were measured at 48 hours post-transfection. (C-D) Sufu over-expression inhibited SRF gene expression, while Sufu knockdown promoted its expression. (E) SRF gene promoter activity is increased by Sufu inhibition. (F) GLI1 binding site within SRF gene promoter region is necessary for SRF gene up-regulation by Sufu knockdown in AdSPCS. The potential wild type binding site (pGL3-SRF-WT) of GLI1 within SRF gene promoter and its mutant pGL3SRF-GLI1 ${ }^{\text {mut }}$ ) are depicted in this illustration (Insert). AdSPCs infected with sh-NT or sh-Sufu lentivirus were transfected with respective SRF gene promoter reporters as indicated. Luciferase activity assay were measured at 48 hours post-transfection. (G) Sufu inhibition increases GLI1 enrichment within SRF gene promoter. ChIP assays were performed using antibody against GLI1 or normal IgG, respectively. PCR amplifications of the adjacent regions were included as additional control for specific promoter DNA enrichment. Data presented here are Mean \pm S.E.M of five or six independent experiments ( $n=5$ or 6 , unpaired t-test).

Additional file 9: Figure S8. miR-214 decreases iSMCs during arterial remodelling. After wire-induced femoral arterial injury, $100 \mu$ of 30\% pluronic gel containing $2.5 \mathrm{nmol}$ control AgomiR (Cel-miR-67) or miR-214 AgomiR (miR-214) per artery per mouse was immediately applied and packed around the injured femoral arteries. Two weeks later, injured segments of femoral arteries were harvested for H\&E staining analyses. Mice underwent a sham arterial injury procedure serve as control (Sham). SMCS and neointima (NI) cells were isolated from media of sham mice (SMCS/ Sham) or media/neointima layers of injured mice received control (NI cells/Cel-miR-67) or miR-214 (NI cells/miR-214) AgomiR, respectively. Isolated cells were cultured in SMC medium for 5-7 days and subjected to various analyses as indicated. (B) Phase-contrast images were also taken prior to other analyses and included here. (C \& D) Immunofluorescence staining assays with antibodies against SMaA and IL-6. Representative images (C) and percentage of iSMCs from each group ((D) were presented here. (E) RT-qPCR detection of gene expression. Data presented here are representative images or Mean \pm S.E.M of five independent experiments $(\mathrm{n}=5) .{ }^{*} P<0.05$ (versus sham), ${ }^{\#} \mathrm{P}<0.05$ (miR-214 versus Cel-miR-67) (oneway ANOVA with a post hoc test of Tukey's analysis). miR-214 indicates miR-214-3p.

Additional file 10: Figure S9. Transplanted AdSPCs differentiate



contained $1 \times 10^{6}$ AdSPCs infected with Lenti-GFP per vessel per mice was immediately applied and packed around injured vessel. One week later, injured segments of femoral arteries were harvested and prepared, followed by triple immunofluorescence staining with antibodies against GFP, SMaA and S100A4. White arrows within merged image indicate iSMCs derived from transplanted AdSPCs. Data presented here are representative images from three mice.

\section{Abbreviations}

miR-214-3p: MicroRNA-214-3p; Sufu: Suppressor of fused; SRF: Serum response factor; Shh: Sonic hedgehog; GLI1: Glioma-associated oncogene 1; SMC: Smooth muscle cell; iSMC: Inflammatory smooth muscle cell; RSMC: Rhomboid SMC; AdSPCs: Adventitial stem/progenitor cells; TGF $\beta 1$ : Transforming growth factor beta1; TNFa: Tumour necrosis factor alpha; IFNY: Interferon gamma; MCP-1: Monocyte chemoattractant protein 1; SMaA: Smooth muscle a actin; SM22a: Smooth muscle 22a; SMmyh11: Smooth muscle myosin heavy chain 11; SM-MHC: Smooth muscle myosin heavy chain; S100A4: S100 calcium-binding protein A4;

FSP1: Fibroblast-specific protein 1; Sox10 or 17: SRY-box transcription factor 10 or 17; 3'UTR: 3'-Untranslated region; BS: Binding site; shRNA: Short hairpin RNA; ChIP: Chromatin immunoprecipitation; GFP: Green fluorescent protein; RT-qPCR: Real-time quantitative PCR; Cel-miR-67 AgomiR: Caenorhabditis elegans miR-67 AgomiR; FA: Femoral artery; NI: Neointima

\section{Acknowledgements}

None

\section{Authors' contributions}

$\mathrm{SH}$ and FY carried out the majority of cellular and molecular genetic studies, immunostaining and data analysis. MY helped to conduct the animal experiments and human aortic gene analysis. WA carried out the vector construction and the immunoassays. EMM and RX helped to draft the manuscript and critical reviewing. QC participated in the AdSPC isolation, characterisation and differentiation. WWu participated in the design of the study and performed the statistical analysis. LZ, WW and QX conceived the study, participated in its design and coordination and helped to draft the manuscript. All authors read and approved the final manuscript.

\section{Funding}

This work was supported by the British Heart Foundation (PG/15/11/31279, $\mathrm{PG} / 15 / 86 / 31723$ and $\mathrm{PG} / 16 / 1 / 31892$ ), National Natural Science Foundation of China (81930010, 81870206 and 81800248), Natural Science Foundation of Zhejiang Province (LD18H020001) and Project of Medical Science Research Foundation from Health Department of Zhejiang Province (2019RC166). This work forms part of the research portfolio for the National Institute for Health Research Biomedical Research Centre at Barts.

\section{Availability of data and materials}

Some data/material may not be made available because of privacy or ethical restrictions. All remaining data are contained within the article.

\section{Ethics approval and consent to participate}

For detecting the gene expression levels of miR-214-3p and Sufu in human aortic tissues, the existing materials (RNA) from previous studies were used in this study. All patients gave their written, informed consent prior to inclusion in the study. All procedures had local ethical approval (2013/150). All studies were approved by the Research Ethics Committees of the First Affiliated Hospital of Zhejiang University, China, and all experiments were conducted according to the principles expressed in the Declaration of Helsinki. All animal experiments were conducted according to the Animals (Scientific Procedures) Act of 1986 (UK). All the animal procedures were approved by Queen Mary University of London ethics review board (PPL number: PB508B78D) and conform to the guidelines from Directive 2010/63/EU of the European Parliament on the protection of animals used for scientific purposes or the NIH guidelines (guide for the care and use of laboratory animals).

Consent for publication

Not applicable 


\section{Competing interests}

The authors declare that they have no competing interests.

\begin{abstract}
Author details
${ }^{1}$ Centre for Clinical Pharmacology, William Harvey Research Institute, Barts and The London School of Medicine and Dentistry, Queen Mary University of London, London EC1M 6BQ, UK. ${ }^{2}$ Institute of Bioengineering, School of Engineering and Materials Science, Queen Mary University of London, London EC1M 6BQ, UK. ${ }^{3}$ Department of Cardiology, The First Affiliated Hospital, School of Medicine, Zhejiang University, 79 Qingchun Road, Hangzhou 310003, Zhejiang, China. ${ }^{4}$ Department of Cardiology, and Institute for Cardiovascular Development and Regenerative Medicine, Xinhua Hospital Affiliated to Shanghai Jiaotong University School of Medicine, Shanghai 200092, China. ${ }^{5}$ Key Laboratory of Cardiovascular Diseases at The Second Affiliated Hospital, School of Basic Medical Sciences, Guangzhou Medical University, Xinzao Town, Panyu District, Guangzhou, Guangdong 511436, China. ${ }^{6}$ Guangzhou Municipal and Guangdong Provincial Key Laboratory of Protein Modification and Degradation, School of Basic Medical Sciences, Guangzhou Medical University, Xinzao Town, Panyu District, Guangzhou 511436, Guangdong, China.
\end{abstract}

Received: 18 August 2020 Accepted: 21 October 2020 Published online: 03 November 2020

\section{References}

1. Bochaton-Piallat ML, Back M. Novel concepts for the role of smooth muscle cells in vascular disease: towards a new smooth muscle cell classification. Cardiovasc Res. 2018;114:477-80.

2. Bentzon JF, Majesky MW. Lineage tracking of origin and fate of smooth muscle cells in atherosclerosis. Cardiovasc Res. 2018;114:492-500.

3. Allahverdian S, Chaabane C, Boukais K, Francis GA, Bochaton-Piallat ML. Smooth muscle cell fate and plasticity in atherosclerosis. Cardiovasc Res. 2018:114:540-50.

4. Ni Z, Deng J, Potter CMF, Nowak WN, Gu W, Zhang Z, Chen T, Chen Q, Hu Y, Zhou B, Xu Q, Zhang L. Recipient c-kit lineage cells repopulate smooth muscle cells of transplant arteriosclerosis in mouse models. Circ Res. 2019; 125:223-41.

5. Dong XR, Brewer CM, Majesky MW. Origins of smooth muscle progenitor cells in transplant arteriosclerosis. Circ Res. 2019:125:242-4.

6. Yang F, Chen Q, Yang M, Maguire EM, Yu X, He S, Xiao R, Wang CS, An W, Wu W, Zhou Y, Xiao Q, Zhang L. Macrophage-derived MMP-8 determines smooth muscle cell differentiation from adventitia stem/progenitor cells and promotes neointima hyperplasia. Cardiovasc Res. 2020;116:211-25.

7. Hu Y, Zhang Z, Torsney E, Afzal AR, Davison F, Metzler B, Xu Q. Abundant progenitor cells in the adventitia contribute to atherosclerosis of vein grafts in ApoE-deficient mice. J Clin Invest. 2004:113:1258-65.

8. Zoll J, Fontaine V, Gourdy P, Barateau V, Vilar J, Leroyer A, Lopes-Kam I, Mallat Z, Arnal JF, Henry P, Tobelem G, Tedgui A. Role of human smooth muscle cell progenitors in atherosclerotic plaque development and composition. Cardiovasc Res. 2008:77:471-80.

9. Chen Y, Wong MM, Campagnolo P, Simpson R, Winkler B, Margariti A, Hu Y, $\mathrm{Xu} \mathrm{Q}$. Adventitial stem cells in vein grafts display multilineage potential that contributes to neointimal formation. Arterioscler Thromb Vasc Biol. 2013;33: 1844-51.

10. Tang Z, Wang A, Yuan F, Yan Z, Liu B, Chu JS, Helms JA, Li S. Differentiation of multipotent vascular stem cells contributes to vascular diseases. Nat Commun. 2012:3:875.

11. Tang Z, Wang A, Wang D, Li S. Smooth muscle cells: to be or not to be? Response to Nguyen et al. Circ Res. 2013;112:23-6.

12. Grudzinska MK, Kurzejamska E, Bojakowski K, Soin J, Lehmann MH, Reinecke H, Murry CE, Soderberg-Naucler C, Religa P. Monocyte chemoattractant protein 1-mediated migration of mesenchymal stem cells is a source of intimal hyperplasia. Arterioscler Thromb Vasc Biol. 2013:33:1271-9.

13. Tanaka K, Sata M, Hirata Y, Nagai R. Diverse contribution of bone marrow cells to neointimal hyperplasia after mechanical vascular injuries. Circ Res. 2003:93:783-90

14. Daniel JM, Sedding DG. Circulating smooth muscle progenitor cells in arterial remodeling. J Mol Cell Cardiol. 2011;50:273-9.

15. Iwata H, Manabe I, Fujiu K, Yamamoto T, Takeda N, Equchi K, Furuya A, Kuro-o M, Sata M, Nagai R. Bone marrow-derived cells contribute to vascular inflammation but do not differentiate into smooth muscle cell lineages. Circulation. 2010;122:2048-57.

16. Daniel JM, Bielenberg W, Stieger P, Weinert S, Tillmanns H, Sedding DG. Time-course analysis on the differentiation of bone marrow-derived progenitor cells into smooth muscle cells during neointima formation. Arterioscler Thromb Vasc Biol. 2010;30:1890-6.

17. Gareri C, De Rosa S, Indolfi C. MicroRNAs for restenosis and thrombosis after vascular injury. Circ Res. 2016;118:1170-84.

18. Yang F, Chen Q, He S, Yang M, Maguire EM, An W, Afzal TA, Luong LA, Zhang L, Xiao Q. miR-22 is a novel mediator of vascular smooth muscle cell phenotypic modulation and neointima formation. Circulation. 2018;137: 1824-41.

19. Zhao H, Wen G, Huang Y, Yu X, Chen Q, Afzal TA, Luong le A, Zhu J, Ye S, Zhang $L$, Xiao $Q$. MicroRNA-22 regulates smooth muscle cell differentiation from stem cells by targeting methyl CpG-binding protein 2. Arterioscler Thromb Vasc Biol. 2015;35:918-29.

20. Yu X, Zhang L, Wen G, Zhao H, Luong LA, Chen Q, Huang Y, Zhu J, Ye S, Xu Q, Wang W, Xiao Q. Upregulated sirtuin 1 by miRNA-34a is required for smooth muscle cell differentiation from pluripotent stem cells. Cell Death Differ. 2015;22:1170-80.

21. Chen Q, Yang F, Guo M, Wen G, Zhang C, Luong le A, Zhu J, Xiao Q, Zhang L. miRNA-34a reduces neointima formation through inhibiting smooth muscle cell proliferation and migration. J Mol Cell Cardiol. 2015;89:75-86.

22. Zhang L, Chen Q, An W, Yang F, Maguire EM, Chen D, Zhang C, Wen G, Yang M, Dai B, Luong LA, Zhu J, Xu Q, Xiao Q. Novel pathological role of hnRNPA1 (heterogeneous nuclear ribonucleoprotein A1) in vascular smooth muscle cell function and neointima hyperplasia. Arterioscler Thromb Vasc Biol. 2017:37:2182-94.

23. Elia L, Quintavalle M, Zhang J, Contu R, Cossu L, Latronico MV, Peterson KL, Indolf C, Catalucci D, Chen J, Courtneidge SA, Condorelli G. The knockout of miR-143 and -145 alters smooth muscle cell maintenance and vascular homeostasis in mice: correlates with human disease. Cell Death Differ. 2009;16:1590-8.

24. Boettger T, Beetz N, Kostin S, Schneider J, Kruger M, Hein L, Braun T. Acquisition of the contractile phenotype by murine arterial smooth muscle cells depends on the Mir143/145 gene cluster. J Clin Invest. 2009:119:2634-47.

25. Aurora AB, Mahmoud Al, Luo X, Johnson BA, van Rooij E, Matsuzaki S, Humphries KM, Hill JA, Bassel-Duby R, Sadek HA, Olson EN. MicroRNA-214 protects the mouse heart from ischemic injury by controlling $\mathrm{Ca}^{2+}$ overload and cell death. J Clin Invest. 2012;122:1222-32.

26. van Mil A, Grundmann S, Goumans MJ, Lei Z, Oerlemans MI, Jaksani S, Doevendans PA, Sluijter JP. MicroRNA-214 inhibits angiogenesis by targeting Quaking and reducing angiogenic growth factor release. Cardiovasc Res. 2012;93:655-65.

27. Flynt AS, Li N, Thatcher EJ, Solnica-Krezel L, Patton JG. Zebrafish miR-214 modulates Hedgehog signaling to specify muscle cell fate. Nat Genet. 2007; 39:259-63.

28. Liu J, Luo XJ, Xiong AW, Zhang ZD, Yue S, Zhu MS, Cheng SY. MicroRNA-214 promotes myogenic differentiation by facilitating exit from mitosis via down-regulation of proto-oncogene N-ras. J Biol Chem. 2010:285:26599-607.

29. Juan AH, Kumar RM, Marx JG, Young RA, Sartorelli V. Mir-214-dependent regulation of the polycomb protein Ezh2 in skeletal muscle and embryonic stem cells. Mol Cell. 2009:36:61-74.

30. van Balkom BW, de Jong OG, Smits M, Brummelman J, den Ouden K, de Bree PM, van Eijndhoven MA, Pegtel DM, Stoorvogel W, Wurdinger T, Verhaar MC. Endothelial cells require miR-214 to secrete exosomes that suppress senescence and induce angiogenesis in human and mouse endothelial cells. Blood. 2013;121(3997-4006):S3991-15.

31. Wang X, Guo B, Li Q, Peng J, Yang Z, Wang A, Li D, Hou Z, Lv K, Kan G, Cao $H$, Wu H, Song J, Pan X, Sun Q, Ling S, Li Y, Zhu M, Zhang P, Peng S, Xie X, Tang T, Hong A, Bian Z, Bai Y, Lu A, He F, Zhang G. miR-214 targets ATF4 to inhibit bone formation. Nat Med. 2013;19:93-100.

32. Afzal TA, Luong LA, Chen D, Zhang C, Yang F, Chen Q, An W, Wilkes E, Yashiro K, Cutillas PR, Zhang L, Xiao Q. NCK associated protein 1 modulated by miRNA-214 determines vascular smooth muscle cell migration, proliferation, and neointima hyperplasia. J Am Heart Assoc. 2016;5(12): e004629. https://doi.org/10.1161/JAHA.116.004629.

33. Nosalski R, Siedlinski M, Denby L, McGinnigle E, Nowak M, Nguyen Dinh Cat A, Medina-Ruiz L, Cantini M, Skiba D, Wilk G, Osmenda G, Rodor J, Salmeron-Sanchez M, Graham G, Maffia P, Graham D, Baker AH, Guzik TJ. T 
cell-derived miRNA-214 mediates perivascular fibrosis in hypertension. Circ Res. 2020;126:988-1003.

34. Shoji M, Sata M, Fukuda D, Tanaka K, Sato T, Iso Y, Shibata M, Suzuki H, Koba S, Geshi E, Katagiri T. Temporal and spatial characterization of cellular constituents during neointimal hyperplasia after vascular injury: potential contribution of bone-marrow-derived progenitors to arterial remodeling. Cardiovasc Pathol. 2004;13:306-12.

35. Sata M, Maejima Y, Adachi F, Fukino K, Saiura A, Sugiura S, Aoyagi T, Imai Y, Kurihara H, Kimura K, Omata M, Makuuchi M, Hirata Y, Nagai R. A mouse model of vascular injury that induces rapid onset of medial cell apoptosis followed by reproducible neointimal hyperplasia. J Mol Cell Cardiol. 2000;32:2097-104.

36. Weiser-Evans MC, Quinn BE, Burkard MR, Stenmark KR. Transient reexpression of an embryonic autonomous growth phenotype by adult carotid artery smooth muscle cells after vascular injury. J Cell Physiol. 2000; 182:12-23.

37. Mourani PM, Garl PJ, Wenzlau JM, Carpenter TC, Stenmark KR, Weiser-Evans MC. Unique, highly proliferative growth phenotype expressed by embryonic and neointimal smooth muscle cells is driven by constitutive Akt, mTOR, and p70S6K signaling and is actively repressed by PTEN. Circulation. 2004; 109:1299-306

38. Majesky MW, Giachelli CM, Reidy MA, Schwartz SM. Rat carotid neointimal smooth muscle cells reexpress a developmentally regulated mRNA phenotype during repair of arterial injury. Circ Res. 1992;71:759-68.

39. Orr AW, Hastings NE, Blackman BR, Wamhoff BR. Complex regulation and function of the inflammatory smooth muscle cell phenotype in atherosclerosis. J Vasc Res. 2010;47:168-80.

40. Brisset AC, Hao H, Camenzind E, Bacchetta M, Geinoz A, Sanchez JC, Chaponnier C, Gabbiani G, Bochaton-Piallat ML. Intimal smooth muscle cells of porcine and human coronary artery express S100A4, a marker of the rhomboid phenotype in vitro. Circ Res. 2007;100:1055-62.

41. Majesky MW, Dong XR, Hoglund V, Daum G, Mahoney WM Jr. The adventitia: a progenitor cell niche for the vessel wall. Cells Tissues Organs. 2012;195:73-81.

42. Passman JN, Dong XR, Wu SP, Maguire CT, Hogan KA, Bautch VL, Majesky MW. A sonic hedgehog signaling domain in the arterial adventitia supports resident Sca $1^{+}$smooth muscle progenitor cells. Proc Natl Acad Sci U S A. 2008;105:9349-54.

43. Kolesova H, Roelink H, Grim M. Sonic hedgehog is required for the assembly and remodeling of branchial arch blood vessels. Dev Dyn. 2008; 237:1923-34.

44. Zhu H, Lo HW. The human glioma-associated oncogene homolog 1 (GLI1) family of transcription factors in gene regulation and diseases. Curr Genomics. 2010;11:238-45.

45. Dunaeva M, Michelson P, Kogerman P, Toftgard R. Characterization of the physical interaction of Gli proteins with SUFU proteins. J Biol Chem. 2003; 278:5116-22.

46. Kogerman P, Grimm T, Kogerman L, Krause D, Unden AB, Sandstedt B, Toftgard R, Zaphiropoulos PG. Mammalian suppressor-of-fused modulates nuclear-cytoplasmic shuttling of Gli-1. Nat Cell Biol. 1999;1:312-9.

47. Lees CW, Zacharias WJ, Tremelling M, Noble CL, Nimmo ER, Tenesa A, Cornelius J, Torkvist L, Kao J, Farrington S, Drummond HE, Ho GT, Arnott ID, Appelman HD, Diehl L, Campbell H, Dunlop MG, Parkes M, Howie SE, Gumucio DL, Satsangi J. Analysis of germline GLI1 variation implicates hedgehog signalling in the regulation of intestinal inflammatory pathways. PLoS Med. 2008;5:e239.

48. Hao H, Ropraz P, Verin V, Camenzind E, Geinoz A, Pepper MS, Gabbiani G, Bochaton-Piallat ML. Heterogeneity of smooth muscle cell populations cultured from pig coronary artery. Arterioscler Thromb Vasc Biol. 2002;22:1093-9.

49. Watanabe T, Sato T, Amano T, Kawamura Y, Kawamura N, Kawaquchi H, Yamashita N, Kurihara H, Nakaoka T. Dnm3os, a non-coding RNA, is required for normal growth and skeletal development in mice. Dev Dyn. 2008;237:3738-48.

50. Herring BP, Hoggatt AM, Griffith SL, McClintick JN, Gallagher PJ. Inflammation and vascular smooth muscle cell dedifferentiation following carotid artery ligation. Physiol Genomics. 2017;49:115-26.

51. Ackers-Johnson M, Talasila A, Sage AP, Long X, Bot I, Morrell NW, Bennett MR, Miano JM, Sinha S. Myocardin regulates vascular smooth muscle cell inflammatory activation and disease. Arterioscler Thromb Vasc Biol. 2015;35:817-28.

52. Liu Q, Li J, Liang Q, Wang D, Luo Y, Yu F, Janicki JS, Fan D. Sparstolonin B suppresses rat vascular smooth muscle cell proliferation, migration, inflammatory response and lipid accumulation. Vasc Pharmacol. 2015;67-69:59-66.
53. Alexander MR, Murgai M, Moehle CW, Owens GK. Interleukin-1ß modulates smooth muscle cell phenotype to a distinct inflammatory state relative to PDGF-DD via NF-KB-dependent mechanisms. Physiol Genomics. 2012:44:417-29.

54. Chen ZG, Liu H, Zhang JB, Zhang SL, Zhao LH, Liang WQ. Upregulated microRNA-214 enhances cardiac injury by targeting ITCH during coxsackievirus infection. Mol Med Rep. 2015;12:1258-64.

55. Mooney CJ, Hakimjavadi R, Fitzpatrick E, Kennedy E, Walls D, Morrow D, Redmond EM, Cahill PA. Hedgehog and resident vascular stem cell fate. Stem Cells Int. 2015;2015:468428.

56. Kramann R, Schneider RK, DiRocco DP, Machado F, Fleig S, Bondzie PA, Henderson JM, Ebert BL, Humphreys BD. Perivascular Gli1 ${ }^{+}$progenitors are key contributors to injury-induced organ fibrosis. Cell Stem Cell. 2015;16:51-66.

\section{Publisher's Note}

Springer Nature remains neutral with regard to jurisdictional claims in published maps and institutional affiliations.
Ready to submit your research? Choose BMC and benefit from:

- fast, convenient online submission

- thorough peer review by experienced researchers in your field

- rapid publication on acceptance

- support for research data, including large and complex data types

- gold Open Access which fosters wider collaboration and increased citations

- maximum visibility for your research: over $100 \mathrm{M}$ website views per year

At BMC, research is always in progress.

Learn more biomedcentral.com/submissions 